\title{
Clostridium difficile-associated diarrhea in radiooncology: an underestimated problem for the feasibility of the radiooncological treatment?
}

\author{
Matthias G Hautmann*, Matthias Hipp and Oliver Kölbl
}

\begin{abstract}
Background and Purpose: Over the last years an increasing incidence of Clostridium difficile-associated diarrhea (CDAD) has been reported. Especially haematology-oncology patients are at risk of developing CDAD.

The aim of this analysis is to determine the incidence of CDAD in radiooncological patients and to find out what relevance CDAD has for the feasibility of the radiooncological treatment, as well as to detect and describe risk factors.

Patients and Methods: In a retrospective analysis from 2006 to 201034 hospitalized radiooncological patients could be identified having CDAD. The risk factors of these patients were registered, the incidence was calculated and the influence on the feasibility of the radiooncological therapy was evaluated. Induced arrangements for prophylaxis of CDAD were identified and have been correlated with the incidence.
\end{abstract}

Results: The incidence of CDAD in our collective is 1,6\%. Most of the patients suffering from a CDAD were treated for carcinoma in the head and neck area. Common risk factors were antibiotics, proton pump inhibitors, cytostatic agents and tube feeding.

Beside a high rate of electrolyte imbalance and hypoproteinemia a decrease of general condition was frequent. 12/ 34 patients had a prolonged hospitalization, in 14/34 patients radiotherapy had to be interrupted due to CDAD. In 21 of 34 patients a concomitant chemotherapy was planned. 4/21 patients could receive all of the planned cycles and only $2 / 21$ patients could receive all of the planned cycles in time.

4/34 patients died due to CDAD. In 4/34 patients an initially curative treatment concept has to be changed to a palliative concept.

With intensified arrangements for prophylaxis the incidence of CDAD decreased from 4,0\% in 2007 to 0,4\% in 2010.

Conclusion: The effect of CDAD on the feasibility of the radiotherapy and a concomitant chemotherapy is remarkable. The morbidity of patients is severe with a high lethality.

Reducing of risk factors, an intense screening and the use of probiotics as prophylaxis can reduce the incidence of CDAD.

Keywords: Clostridium difficile-associated diarrhea, Clostridium difficile, Diarrhea, Colitis, Radiotherapy, Radiation Therapy, Chemoradiation

\section{Background and Purpose}

Clostridium difficile $(\mathrm{CD})$ appears normally as a harmless environmental gram positive anaerobic bacteria which becomes pathogen in several circumstances [1,2]. Clostridium difficile can be isolated from the stool of up to five per cent of healthy adults. Some strains produce

\footnotetext{
* Correspondence: matthias.hautmann@klinik.uni-regensburg.de Institutional address: Department of Radiotherapy, University of Regensburg, Regensburg, Germany
}

toxin and can therefore cause diarrhea [3]. CD is the aetiological agent for most of the cases of pseudo membranous colitis. Over the last years an increasing incidence of Clostridium difficile-associated diarrhea (CDAD) has been reported. Furthermore, more severe courses of the disease have been described because of new virulent strains [3-6].

Several risk factors for CDAD are known. Beside antibiotic intake, other drugs like immunosuppressant, 
cytostatic agents and proton pump inhibitors (PPI) have been identified to trigger CDAD [5,7-10]. Also tube feeding, parenteral nutrition as well as a reduced general condition and compromised immune function have been described as risk factors [1,2,11].

Especially haematology-oncology patients are at risk of developing CDAD [12-15]. Those haematology-oncology patients often have systemic diseases and in many cases receive high dosed chemotherapy.

Radiooncological patients are mostly suffering from localised tumour and receive radiotherapy alone or with a moderate dosed concomitant chemotherapy compared to chemotherapy of haematology patients. Because of the mainly local therapy radiooncological patients have higher local toxicity. Especially stomatitis, mucositis and dysphagia are common in radiooncological patients and might be relevant as risk factors.

In summary a lot of radiooncological patients have several risk factors. Beside concomitant chemotherapy, the frequency of a treatment with PPI and antibiotics is estimated to be high on a radiooncological ward [16-19]. Also tube feeding and parenteral nutrition is common [20-22].

CDAD has a lethality of $0.5 \%$ to $2.0 \%$ and an increasing morbidity $[3,14]$. A high morbidity and a negative influence on the treatment of the underlying disease have been documented, especially for surgical patients or patients on intensive care units [23,24]. A high number of acute renal failure, weight loss, electrolyte imbalance and hypoproteinemia have been described $[5,23]$.

The influence of CDAD for the treatment of oncological patients is not well reviewed. Because of the existing data, multiple problems for the treatment of those patients can be assumed [25,26].

Often inpatient stay is prolonged because of CDAD. The costs for the health care system are high. There are data showing estimated additional costs between 5243 US\$ and 8570 US\$ in Europe per patient with a primary episode of CDAD and over 13600 US\$ for a case of recurrent CDAD [5,27].

Referring to this data, there might be a negative influence on the feasibility of a radiooncological treatment for patients suffering from a CDAD.

The aim of this analysis is to determine the incidence of CDAD in radiooncological patients and to find out what relevance CDAD has for the feasibility of the radiooncological treatment, as well as to detect and describe risk factors.

\section{Patients and Methods}

The study was performed for patients of a department of radiotherapy of a German university hospital. In- and outpatients were looked up for CDAD. Only inpatients could be identified developing CDAD during radiooncological treatment.

In a retrospective analysis from 2006 to 201034 hospitalized radiooncological patients could be identified having CDAD. In that time 2150 patients were on the radiooncological ward in total (484 in 2006, 398 in 2007, 423 in 2008, 384 in 2009 and 461 in 2010).

Radiooncological inpatients were identified from CD positive patients registered in the department for microbiology and hygiene. Beside that, the enquiry was done by checking codification for final payment. All patients had to have at least one stool sample being tested positive for $\mathrm{CD}$ toxin $\mathrm{A}$ or $\mathrm{B}$.

Until the year 2008 all inpatients with watery diarrhea of more than 24 hours and all patients with medical history of antibiotic intake and non-watery diarrhea of more than 48 hours were screened for CDAD. Beside that all patients with any diarrhea of more than 72 hours were screened for CDAD. For all patients a stool sample was collected and screened for Clostridium difficile toxin A and B by enzyme immunoassay.

Since 2008 for all patients with any diarrhea longer than 24 hours were screened for $C D$ toxin $A$ and $B$. In case of clinical suspicion of CDAD and negative findings for CD toxin A or B, two more stool samples were screened by enzyme immunoassay.

Since 2009 for all patients a stool sample was cultured for toxigenic $C D$ additionally to the enzyme immunoassay.

All patients with positive findings for $\mathrm{CD}$ toxin $\mathrm{A}$ or $\mathrm{B}$ had clinical symptoms of CDAD. In our collective no asymptomatic carrier could be identified.

In case of suspicion of a relapse of CDAD, beside screening for CD toxin A and B, a sigmoidoscopy was performed and a stool sample was cultured for toxigenic CD.

The risk factors of the patients were registered. Antibiotics and cytostatic agents applicated up to four weeks prior to diagnosis of CDAD were assessed. Patients with a long time medication of immunosuppressive drugs or patients with a Leukopenia CTC grade IV were counted as immunosupressed. The influence on the feasibility of the radiooncological therapy in terms of interruption or abandonment of the radiotherapy, change of therapy concept and the effect on the feasibility of chemotherapy were evaluated.

Induced arrangements for prophylaxis of CDAD were identified and have been correlated with the incidence.

\section{Results}

\section{Patient's characteristics}

The incidence of CDAD in our collective is 1,6\% (34 of 2150 patients). Of the 34 patients having a CDAD, 
24 were male, 10 were female. The median age was 67 Years with a standard deviation of 10 Years (Range from 46 to 85 years).

Most patients suffered from a head and neck cancer or metastases in the head and neck area.

Treatment areas were in 21 cases the head and neck. 7 patients were treated thoracically, 5 pelvic and one abdominal (Table 1).

The average treatment time was 41 days with a standard deviation of 19 days (Range from 5 to 74 days). The average time as inpatients was 36 days with a standard deviation of 22 days (Range from 2 to 80 days).

\section{Risk factors}

The following data in terms of risk factors were collected: The median pre treatment Karnofsky

\section{Table 1 Patient characteristics}

\begin{tabular}{|c|c|c|}
\hline & sex & Underlying disease \\
\hline 1 & $\mathrm{~F}$ & Anaplastic thyroid carcinoma \\
\hline 2 & M & Squamous cell carcinoma of the head and neck (SCCHN) \\
\hline 3 & F & Thyroid metastasis of an renal cell carcinoma \\
\hline 4 & M & $\mathrm{SCCHN}$ \\
\hline 5 & $\mathrm{~F}$ & Cervical carcinoma \\
\hline 6 & M & SCCHN \\
\hline 7 & M & Bronchial carcinoma with a simultaneous SCCHN \\
\hline 8 & $\mathrm{~F}$ & $\mathrm{SCCHN}$ \\
\hline 9 & M & Bronchial carcinoma \\
\hline 10 & M & $\mathrm{SCCHN}$ \\
\hline 11 & M & SCCHN \\
\hline 12 & F & $\mathrm{SCCHN}$ \\
\hline 13 & M & Bronchial carcinoma \\
\hline 14 & M & M. Hodgkin \\
\hline 15 & M & Bronchial carcinoma \\
\hline 16 & M & SCCHN \\
\hline 17 & M & Anal carcinoma \\
\hline 18 & M & Bronchial carcinoma \\
\hline 19 & F & Giant cell B-NHL with an abdominal bulk \\
\hline 20 & M & $\mathrm{SCCHN}$ \\
\hline 21 & $\mathrm{~F}$ & Rectal carcinoma \\
\hline 22 & M & SCCHN \\
\hline 23 & M & $\mathrm{SCCHN}$ \\
\hline 24 & M & $\mathrm{SCCHN}$ \\
\hline 25 & M & Oesophageal carcinoma \\
\hline 26 & M & SCCHN \\
\hline 27 & $\mathrm{~F}$ & $\mathrm{SCCHN}$ \\
\hline 28 & M & SCCHN \\
\hline 29 & $\mathrm{~F}$ & Cervical carcinoma \\
\hline 30 & M & Pelvine bone metastasis of a rectal carcinoma \\
\hline 31 & M & Oesophageal carcinoma \\
\hline 32 & $\mathrm{~F}$ & SCCHN \\
\hline 33 & M & SCCHN \\
\hline 34 & $M$ & SCCHN \\
\hline
\end{tabular}

Performance Status (KPS) of the patients was $70 \%$ (range from $40 \%$ to $100 \%$ ).

Twenty patients out of 34 (59\%) had an antibiotic treatment up to four weeks before developing diarrhea.

The most common antibiotic being taken was Piperacillin/Combactam with $29 \%$ of all patients (10/34 patients) and $50 \%$ of the patients having an antibiotic treatment (10/20). Beside Piperacillin/Combactam, Ciprofloxacin (24\% of all patients (8/34), $40 \%$ of the patients receiving antibiotics $(8 / 20))$ and Moxifloxacin (18\% (6/34), 30\% (6/20)) were frequently used. In 2006 and 2007 Moxifloxacin was frequently given. 45\% (5/11) of the patients with antibiotic treatment in that period received Moxifloxacin. Since suspicions arose that Moxifloxacin triggers CDAD, in an antibiotic stewardship Moxifloxacin wasn't given in routine since 2008. Only one more patient since 2007 developed a CD infection after receiving Moxifloxacin.

Beside antibiotics, PPI, cytostatic agents and tube feeding were common in radiooncological patients.

Of the 18 patients with nutrition via gastric tube, 14 had tube feeding as the only food intake. There was no patient on parenteral nutrition as the only food intake (Table 2).

\section{Treatment of CDAD}

For all patients with CDAD therapy with PPI, antibiotics and cytostatic agents was paused or stopped if possible. In two patients no further antibiotic treatment for CD was necessary. Since 2007 all patients were treated with probiotics (Saccharomyces boulardii) until there were no more clinical symptoms for two days.

Following the guidelines and recommendations of the Robert Koch Institute patients were treated with metronidazole as the first line therapy to avoid vancomycin resistant enterococci. According to the dysphagia of the patients metronidazole was given oral, via gastric tube or parenteral.

Patients with a severe diarrhea, with a KPS of less than $60 \%$ or with more than two episodes of CDAD were treated with oral vancomycin as first line therapy.

If the symptoms did not disappear within five days of treatment with metronidazole the therapy was changed to vancomycin. 4 Patients were treated with combination of parenteral metronidazole and enteral vancomycin.

The average treatment time with antibiotics was 15 days (range from 5 to 83 days).

\section{Arrangements for prophylaxis}

Since 2008 the arrangements for prophylaxis have been intensified. Antibiotics and PPI were restricted in use. Tube feeding and parenteral nutrition as the only food intake was avoided. All patients with diarrhea 
Table 2 Risk Factors

\begin{tabular}{|c|c|c|c|c|c|c|c|c|}
\hline & Age [years] & KPS & Antibiotic treatment & PPI & Cytostatic agents & Tube feeding & Parenteral nutrition & Immuno-suppression \\
\hline 1 & 85 & $40 \%$ & + & + & - & + & - & - \\
\hline 2 & 51 & $60 \%$ & - & + & + & + & - & - \\
\hline 3 & 69 & $60 \%$ & + & + & - & - & - & - \\
\hline 4 & 71 & $60 \%$ & + & + & - & + & - & - \\
\hline 5 & 46 & $90 \%$ & - & - & + & - & - & - \\
\hline 6 & 53 & $70 \%$ & - & + & + & + & + & - \\
\hline 7 & 67 & $80 \%$ & + & + & + & - & - & - \\
\hline 8 & 70 & $70 \%$ & - & + & + & + & - & - \\
\hline 9 & 66 & $70 \%$ & + & + & - & - & - & - \\
\hline 10 & 63 & $60 \%$ & + & - & + & + & + & \\
\hline 11 & 81 & $60 \%$ & + & - & - & - & + & - \\
\hline 12 & 82 & $70 \%$ & + & + & + & + & - & - \\
\hline 13 & 70 & $50 \%$ & + & + & - & - & - & - \\
\hline 14 & 46 & $80 \%$ & - & + & + & - & + & - \\
\hline 15 & 67 & $60 \%$ & + & + & + & - & - & + \\
\hline 16 & 60 & $80 \%$ & - & - & + & - & - & - \\
\hline 17 & 59 & $60 \%$ & + & + & + & - & - & - \\
\hline 18 & 64 & $60 \%$ & + & + & + & - & - & + \\
\hline 19 & 68 & $70 \%$ & + & + & + & - & - & + \\
\hline 20 & 52 & $70 \%$ & - & + & + & + & - & - \\
\hline 21 & 81 & $50 \%$ & - & + & - & - & - & - \\
\hline 22 & 56 & $80 \%$ & - & - & + & + & - & - \\
\hline 23 & 61 & $70 \%$ & - & + & - & + & - & - \\
\hline 24 & 71 & $90 \%$ & - & - & + & + & - & - \\
\hline 25 & 74 & $100 \%$ & - & - & + & - & - & - \\
\hline 26 & 64 & $50 \%$ & - & + & - & + & - & - \\
\hline 27 & 69 & $70 \%$ & + & + & + & + & - & + \\
\hline 28 & 70 & $70 \%$ & + & + & - & + & - & - \\
\hline 29 & 57 & $90 \%$ & + & + & + & - & - & - \\
\hline 30 & 60 & $50 \%$ & + & + & + & - & - & - \\
\hline 31 & 85 & $80 \%$ & - & + & + & + & - & - \\
\hline 32 & 73 & $60 \%$ & + & - & - & + & - & - \\
\hline 33 & 75 & $50 \%$ & + & + & - & + & - & + \\
\hline 34 & 63 & $70 \%$ & + & + & + & + & - & - \\
\hline
\end{tabular}

continuing longer than 24 hours and clinical suspicion of having CDAD were isolated prophylactically.

Isolation implicates a single room with a separate bathroom. Gloves and special gowns were used by the staff dealing with the patients on the ward and the staff dealing with the patient at the linear accelerator. Additional hand hygiene with water and soap for all persons exiting the isolation room was performed as well as for the staff dealing with the patient at the linear accelerator. Surface disinfection was intensified with sodiumhypochloride.

In consultation with the Department of medical Microbiology and Hygiene in an antibiotic stewardship Moxifloxacin was not used in clinical routine since 2008.
Patients with four or more risk factors received probiotic medication (Saccharomyces boulardii) during the radiooncological treatment. Those patients with one episode of CDAD received probiotic medication for the remaining radiooncological treatment.

The chronological incidence of CDAD showed one patient of 484 in 2006 (incidence 0,2\%), 16 of 398 in 2007 (4,0\%), 11 of 423 in 2008 (2,6\%), 4 of 384 in 2009 $(1,0 \%)$ and 2 of 461 in $2010(0,4 \%)$.

\section{Complications of CDAD}

The effect of CDAD on patient treatment showed 24 of 34 patients $(73 \%)$ with an electrolyte imbalance. Of those patients $15 / 24$ (63\%) had an imbalance on two or more electrolytes. $4 / 34$ patients needed intravenous 
substitution of the electrolytes, the others an oral or enteral substitution.

$27 / 34$ patients $(79 \%)$ developed a hypoproteinemia with a need to treat it in $12 / 27$ (43\%) of these patients.

Initially the median KPS of the patients was $70 \%$. After healing of the CDAD the median KPS was 50\%.

$12 / 34$ patients $(35 \%)$ had a prolonged hospitalization of 7 days in average (range from two to 75 days). The patient with prolonged inhabitation of 75 days had to be treated on intensive care unit for most of the time.

$12 / 34$ patients had more than one episode of CDAD during radiooncological treatment. All of these patients had two episodes except one who had three.

In $14 / 34$ patients (42\%) radiotherapy had to be interrupted because of CDAD. This interruption was four days in average (range one to 27 days).

Of those 14 patients with interruption of radiation the average interruption was 10 days. In two patients radiotherapy could not be restarted.

In 21 of the 34 patients a concomitant chemoradiation was planned. For those 21 patients 89 cycles were planned altogether. $43 \%$ of the chemotherapy cycle ( 38 of 89 cycles) could be applicated.

In $62 \%$ of the cases (13/21 patients) chemotherapy had to be stopped and could not be continued. Only $19 \%$ of the patients $(4 / 21$ patients) could receive all of the planned cycles and only $10 \%$ of the patients $(2 / 21$ patients) could receive all of the planned cycles in time.

In four patients an initially curative concept had to be changed into a palliative treatment concept. A reduced general condition after the CDAD did not allow treating them in the initially planned concept.

Four patients $(12 \%)$ died due to CDAD. One patient died in a septicaemia. Three patients did not recover adequate after the infection and died of complications. Two of the patients were treated with the combination of metronidazole and vancomycin. One patient was treated with vancomycin and for the last patient treatment was started with enteral metronidazole. This patient refused further therapy of CDAD because of the advanced tumour stage and died of septicaemia.

\section{Discussion}

The incidence in our collective is with $1,6 \%$ high compared to data in literature. Reichardt et al. describes an incidence of $0,1 \%$ for Europe and an incidence of $0,1 \%$ to $2 \%$ for the USA [3]. Heinlen et al. could found an incidence of $0,6 \%$ for the USA in the year 2003 [28].

Especially the patients with head and neck cancer have a high risk of developing CDAD. This might be due to a multitude of risk factors. 19/34 of our patients were suffering from a squamous cell carcinoma of the head and neck (SCCHN).
Chemoradiation is a standard treatment for different carcinomas [17,29-31]. Many patients on radiooncological wards have at least this as a major risk factor $[16,17,32]$. Some of these patients develop Neutropenia and are therefore immunocompromised $[18,19]$.

Several underlying diseases, mainly a reduced general condition and compromised immune function have been described as risk factors to develop CDAD [1,11].

Hospitalized radiooncological patients often need an antibiotic or antimycotic medication during radiotherapy $[21,22]$. Beside those risk factors, the frequency of a treatment with proton pump inhibitor is estimated to be quiet high on radiooncological wards. Tube feeding and parenteral nutrition favour the onset of CDAD $[3,33,34]$.

Especially head and neck cancer patients have a high rate of dysphagia [18]. Nearly all patients having a dysphagia of CTC grade II or higher requiring tube feeding or parenteral nutrition [20,35]. Wolff et al. found a rate of dysphagia in head and neck tumour patients of $77 \%$ and a rate of Grad 3 leukopenia or higher of 11\% [18]. In our collective all head and neck cancer patients but 3 were addicted to tube feeding or parenteral nutrition $(18 / 21)$.

There are data identifying underlying diseases of the gastrointestinal tract to be risk factors for CDAD $[2,3]$. Whether abdominal or pelvine radiotherapy triggers CDAD is not known. In our collective only one patient received abdominal and five patients received pelvic radiotherapy.

Some data give evidence that haematological and oncological patients are patients at risk for developing CDAD [12-14]. Most data exist for paediatric oncological units and for bone marrow transplant units $[12,15,36,37]$. In the reports on haematology-oncology patients, that include patients undergoing radiotherapy, no subgroup analysis was done for that collective of patients [13]. In summary there are no data about the risk for radiooncological patients suffering from CDAD.

Our data confirm the assumption that radiooncological patients are also patients at risk for an infection with clostridium difficile.

Several authors have shown a decrease in local control for different tumours due to unplanned interruptions of radiotherapy [38,39]. Bese et al. reported a decrease of $1.4 \%$ per day of unplanned interruption for head and neck carcinomas. SCCHN are common in our collective and often have an interruption of radiotherapy.

$42 \%$ of the patients developing a CDAD need a pause of the radiation. For those patients who have an interruption of the radiotherapy, the average interruption time is ten days. A decrease of loco regional control of 10 to $12 \%$ for one week of interruption has been reported $[38,40]$. 
Beside interruption of radiotherapy patients suffering from CDAD have several additional factors decreasing the feasibility of the oncological treatment like weight loss, incomplete chemotherapy and a decrease of general condition.

For bronchial carcinoma, studies have emphasized the importance of prolonged overall treatment time. One study suspected an increase of the risk of death of $2 \%$ even for a one day break [41]. A statistically significant decrease in overall survival for patients receiving a radiochemotherapy for SCLC could be found [38].

Beside bronchial carcinoma and head and neck cancer, also for cervical carcinoma, anal cancer and several other carcinomas it has been reported that prolongation of overall treatment time and interruption of radiotherapy decreases the loco regional control [38]. For that reason, a CDAD is a serious problem for patients undergoing radiotherapy.

Also the feasibility of chemotherapy concomitant to radiotherapy is important for loco regional control and overall survival [42]. Several authors suspect the cumulative dose of concomitant chemotherapy to be an important prognostic factor $[43,44]$. If you compare the feasibility of chemotherapy in our collective with data in literature, you can find a low cumulative dose for the patients with CDAD [19].

In our collective only $19 \%$ of the patients received the complete chemotherapy dose. For example of the patients receiving Cisplatin only 3 of 13 patients received at least $200 \mathrm{mg} / \mathrm{m}^{2}$ Cisplatin. The poor feasibility of chemotherapy in our collective might decrease the loco regional control and overall survival for patients suffering from a CDAD.

In summary with four patients dying due to CDAD, a change from a curative to a palliative concept in another four patients, CDAD is a severe problem for radiooncological patients. Compared with the lethality of $0,5 \%$ to $2 \%$ described in literature the $11,8 \%$ in our collective (four out of 34 patients) seems to be very high [3]. This might be due to a negative selection of the patients. The average age is high and patients had a high number of risk factors, concomitant diseases and often a reduced general condition.

There are several options reducing the risk of developing CDAD. Beside the restrictive use of antibiotics and proton pump inhibitors, the upkeep of oral nutrition as long as possible is essential in reducing the rate of CDAD. Especially Moxifloxacin, which is known to trigger CDAD, was not used since 2008 in clinical routine $[7,45]$. The high rate of patients in our collective receiving Moxifloxacin until 2007 and the decreasing incidence of CDAD since 2008 seemed to be an effect of discontinuing Moxifloxacin in clinical use.
With these arrangements and an intensive screening for Clostridium difficile the rate of infections has declined from 16 cases in 2007 to 11 in 2008, 4 in 2009 and 2 in 2010.

Even though there is only little evidence in probiotics reducing the rate of CDAD for patients at risk, we treated all patients with four or more risk factors frequently [28,46-49].

\section{Conclusion}

The effect of CDAD on the feasibility of the radiotherapy and a concomitant chemotherapy is remarkable. The morbidity of patients is severe with a high lethality.

Reducing of risk factors, an intense screening and the use of probiotics as prophylaxis can reduce the incidence of CDAD.

\section{List of abbreviations}

CD: Clostridium difficile; CDAD: Clostridium difficile:associated diarrhea; KPS: Karnofsky Performance Status; PPI: Proton pump inhibitor; SCCHN: Squamous cell carcinoma of the head and neck

\section{Authors' contributions}

MGH planned the design of the study, did identify the patients, register the patients' data, correlate the data and drafted the manuscript. MH was participating in identification of patients data. OK participated in planning of the study and its coordination. All authors read and approved the final manuscript.

\section{Competing interests}

The authors declare that they have no competing interests.

Received: 5 April 2011 Accepted: 1 August 2011

Published: 1 August 2011

\section{References}

1. Vaishnavi C: Clinical spectrum \& pathogenesis of Clostridium difficile associated diseases. Indian J Med Res 2010, 131:487-499.

2. Hookman P, Barkin JS: Clostridium difficile associated infection, diarrhea and colitis. World J Gastroenterol 2009, 15:1554-1580.

3. Reichardt C, Chaberny IF, Kola A, Mattner F, Vonberg RP, Gastmeier P: [Dramatic increase of Clostridium difficile-associated diarrhea in Germany: has the new strain PCR-ribotype 027 already reached us?]. Dtsch Med Wochenschr 2007, 132:223-228.

4. Koh TH, Tan AL, Tan ML, Wang G, Song KP: Epidemiology of Clostridium difficile infection in a large teaching hospital in Singapore. Pathology 2007, 39:438-442.

5. DuPont HL, Garey K, Caeiro J, Jiang Z: New advances in Clostridium difficile infection: changing epidemiology, diagnosis, treatment and control. Curr Opin Infect Dis 2008, 21:500-507.

6. Kuijper EJ, Barbut F, Brazier JS, Kleinkauf N, Eckmanns T, Lambert ML, Drudy D, Fitzpatrick F, Wiuff C, Brown DJ, Coia JE, Pituch H, Reichert P, Even J, Mossong J, Widmer AF, Olsen KE, Allerberger F, Notermans DW, Delmée M, Coignard B, Wilcox M, Patel B, Frei R, Nagy E, Bouza E, Marin M, Akerlund T, Virolainen-Julkunen A, Lyytikäinen O, Kotila S, Ingebretsen A, Smyth B, Rooney P, Poxton IR, Monnet DL: Update of Clostridium difficile infection due to PCR ribotype 027 in Europe, 2008. Euro Surveill 2008, 13.

7. Thomas C, Stevenson M, Riley TV: Antibiotics and hospital-acquired Clostridium difficile-associated diarrhoea: a systematic review. J Antimicrob Chemother 2003, 51:1339-1350.

8. Kaier K, Frank U: Relationship between antibiotic consumption and Clostridium difficile-associated diarrhea: an epidemiological note. Antimicrob Agents Chemother 2009, 53:4574-4575. 
9. Kim JW, Lee KL, Jeong JB, Kim BG, Shin S, Kim JS, Jung HC, Song IS: Proton pump inhibitors as a risk factor for recurrence of Clostridium-difficileassociated diarrhea. World J Gastroenterol 2010, 16:3573-3577.

10. Aseeri M, Schroeder T, Kramer J, Zackula R: Gastric acid suppression by proton pump inhibitors as a risk factor for clostridium difficile-associated diarrhea in hospitalized patients. Am J Gastroenterol 2008, 103:2308-2313.

11. Vesta KS, Wells PG, Gentry CA, Stipek WJ: Specific risk factors for Clostridium difficile-associated diarrhea: a prospective, multicenter, case control evaluation. Am J Infect Control 2005, 33:469-472.

12. Gifford AH, Kirkland KB: Risk factors for Clostridium difficile-associated diarrhea on an adult hematology-oncology ward. Eur J Clin Microbiol Infect Dis 2006, 25:751-755.

13. Blot E, Escande M, Besson D, Barbut F, Granpeix C, Asselain B, Falcou MC, Pouillart P: Outbreak of Clostridium difficile-related diarrhoea in an adult oncology unit: risk factors and microbiological characteristics. J Hosp Infect 2003, 53:187-192

14. Hornbuckle K, Chak A, Lazarus HM, Cooper GS, Kutteh LA, Gucalp R, Carlisle PS, Sparano J, Parker P, Salata RA: Determination and validation of a predictive model for Clostridium difficile diarrhea in hospitalized oncology patients. Ann Oncol 1998, 9:307-311.

15. Tai E, Richardson LC, Townsend J, Howard E, McDonald LC: Clostridium difficile Infection Among Children With Cancer. Pediatr Infect Dis J 2011, 30:610-612.

16. Patyánik M, Nemeskéri C, Póti Z, Sinkó D, Pesznyák C, Király R, Kois R, Mayer A: Concomitant radiochemotherapy of cervical cancer: is it justified to reduce the dosage of cisplatin? Strahlenther Onkol 2009, 185:582-587.

17. Bernier J: Current state-of-the-art for concurrent chemoradiation. Semin Radiat Oncol 2009, 19:3-10.

18. Wolff HA, Bosch J, Jung K, Overbeck T, Hennies S, Matthias C, Hess CF, Roedel RM, Christiansen H: High-grade acute organ toxicity as positive prognostic factor in primary radio(chemo)therapy for locally advanced, inoperable head and neck cancer. Strahlenther Onkol 2010, 186:262-268.

19. Steinmann D, Cerny B, Karstens JH, Bremer M: Chemoradiotherapy with weekly cisplatin $40 \mathrm{mg} / \mathrm{m}(2)$ in 103 head-and-neck cancer patients: a cumulative dose-effect analysis. Strahlenther Onkol 2009, 185:682-688.

20. Manikantan K, Khode S, Sayed SI, Roe J, Nutting CM, Rhys-Evans P, Harrington KJ, Kazi R: Dysphagia in head and neck cancer. Cancer Treat Rev 2009, 35:724-732

21. Wurstbauer K, Merz F, Sedlmayer F: Amphotericin B lozengers: prophylaxis for esophagitis in thoracic radiotherapy: a prospective study. Strahlenther Onkol 2009, 185:512-516.

22. Semrau $S$, Waldfahrer $F$, Lell $M$, Linke $R$, Klautke $G$, Kuwert $T$, Uder $M$, Iro $H$, Fietkau R: Feasibility, Toxicity, and Efficacy of Short Induction Chemotherapy of Docetaxel Plus Cisplatin or Carboplatin (TP) Followed by Concurrent Chemoradio - therapy for Organ Preservation in Advanced Cancer of the Hypopharynx, Larynx, and Base of Tongue. Early Results. Strahlentherapie und Onkologie: Organ der Deutschen Rontgengesellschaft ... [et al] 2010.

23. Anand A, Bashey B, Mir T, Glatt AE: Epidemiology, clinical manifestations, and outcome of Clostridium difficile-associated diarrhea. Am J Gastroenterol 1994, 89:519-523.

24. Crabtree T, Aitchison D, Meyers BF, Tymkew H, Smith JR, Guthrie TJ, Munfakh N, Moon MR, Pasque MK, Lawton J, Moazami N, Damiano RJ Jr: Clostridium difficile in cardiac surgery: risk factors and impact on postoperative outcome. Ann Thorac Surg 2007, 83:1396-1402.

25. Yamazawa K, Kanno H, Seki K, Kuzuta T, Matsui H, Sekiya S: Life-threatening Clostridium difficile-associated diarrhea induced by paclitaxel-carboplatin combination chemotherapy. Acta Obstet Gynecol Scand 2001, 80:768-769.

26. Resnik E, Lefevre CA: Fulminant Clostridium difficile colitis associated with paclitaxel and carboplatin chemotherapy. Int J Gynecol Cancer 1999, 9:512-514.

27. Ghantoji SS, Sail K, Lairson DR, DuPont HL, Garey KW: Economic healthcare costs of Clostridium difficile infection: a systematic review. J Hosp Infect 2010, 74:309-318.

28. Heinlen L, Ballard JD: Clostridium difficile infection. Am J Med Sci 2010, 340:247-252

29. Fraunholz I, Rabeneck D, Weiss C, Rödel C: Combined-modality treatment for anal cancer: current strategies and future directions. Strahlenther Onkol 2010, 186:361-366.

30. Platteaux N, Dirix P, Vanstraelen B, Nuyts S: Outcome after Re-Irradiation of Head and Neck Cancer Patients. Strahlentherapie und Onkologie: Organ der Deutschen Rontgengesellschaft ... [et al] 2010.
31. Wolf M, Zehentmayr F, Niyazi M, Ganswindt U, Haimerl W, Schmidt M, Hölzel D, Belka C: Long-term outcome of mitomycin C- and 5-FU-based primary radiochemotherapy for esophageal cancer. Strahlenther Onkol 2010, 186:374-381.

32. Huguenin P, Glanzmann C, Taussky D, Lütolf UM, Schmid S, Moe K: Hyperfractionated radiotherapy and simultaneous cisplatin for stage-III and -IV carcinomas of the head and neck. Long-term results including functional outcome. Strahlenther Onkol 1998, 174:397-402.

33. Bliss DZ, Johnson S, Savik K, Clabots CR, Willard K, Gerding DN: Acquisition of Clostridium difficile and Clostridium difficile-associated diarrhea in hospitalized patients receiving tube feeding. Ann Intern Med 1998, 129:1012-1019.

34. O'Keefe SJD: Tube feeding, the microbiota, and Clostridium difficile infection. World J Gastroenterol 2010, 16:139-142.

35. Beckmann GK, Hoppe F, Pfreundner L, Flentje MP: Hyperfractionated accelerated radiotherapy in combination with weekly cisplatin for locally advanced head and neck cancer. Head Neck 2005, 27:36-43.

36. Chopra T, Alangaden GJ, Chandrasekar P: Clostridium difficile infection in cancer patients and hematopoietic stem cell transplant recipients. Expert Rev Anti Infect Ther 2010, 8:1113-1119.

37. Leung S, Metzger BS, Currie BP: Incidence of Clostridium difficile infection in patients with acute leukemia and lymphoma after allogeneic hematopoietic stem cell transplantation. Infect Control Hosp Epidemiol 2010, 31:313-315.

38. Bese NS, Hendry J, Jeremic B: Effects of prolongation of overall treatment time due to unplanned interruptions during radiotherapy of different tumor sites and practical methods for compensation. Int I Radiat Oncol Biol Phys 2007, 68:654-661.

39. van den Bogaert $W$, van der Leest $A$, Rijnders $A$, Delaere $P$, Thames $H$, van der Schueren E: Does tumor control decrease by prolonging overall treatment time or interrupting treatment in laryngeal cancer? Radiother Oncol 1995, 36:177-182.

40. Maciejewski B, Preuss-Bayer G, Trott KR: The influence of the number of fractions and of overall treatment time on local control and late complication rate in squamous cell carcinoma of the larynx. Int J Radiat Oncol Biol Phys 1983, 9:321-328.

41. Machtay M, Hsu C, Komaki R, Sause WT, Swann RS, Langer CJ, Byhardt RW, Curran WJ: Effect of overall treatment time on outcomes after concurrent chemoradiation for locally advanced non-small-cell lung carcinoma: analysis of the Radiation Therapy Oncology Group (RTOG) experience. Int J Radiat Oncol Biol Phys 2005, 63:667-671.

42. Pignon J, Le Maître A, Maillard E, Bourhis J: Meta-analysis of chemotherapy in head and neck cancer (MACH-NC): an update on 93 randomised trials and 17,346 patients. Radiother Oncol 2009, 92:4-14.

43. Foote: The Importance of Planned Dose of Chemotherapy on Time: Do We Need to Change Our Clinical Practice? Oncologist 1998, 3:365-368.

44. Ho KF, Swindell R, Brammer CV: Dose intensity comparison between weekly and 3-weekly Cisplatin delivered concurrently with radical radiotherapy for head and neck cancer: a retrospective comparison from New Cross Hospital, Wolverhampton, UK. Acta Oncol 2008, 47:1513-1518.

45. Pépin J, Saheb N, Coulombe M, Alary ME, Corriveau MP, Authier S, Leblanc M, Rivard G, Bettez M, Primeau V, Nguyen M, Jacob CE, Lanthier L: Emergence of fluoroquinolones as the predominant risk factor for Clostridium difficile-associated diarrhea: a cohort study during an epidemic in Quebec. Clin Infect Dis 2005, 41:1254-1260.

46. Miller K, Fraser T: Q: What is the role of probiotics in the treatment of acute Clostridium difficile-associated diarrhea? Cleve Clin J Med 2009, 76:391-392.

47. Pillai A, Nelson R: Probiotics for treatment of Clostridium difficileassociated colitis in adults. Cochrane Database Syst Rev 2008, CD004611.

48. Segarra-Newnham M: Probiotics for Clostridium difficile-associated diarrhea: focus on Lactobacillus rhamnosus GG and Saccharomyces boulardii. Ann Pharmacother 2007, 41:1212-1221.

49. Monaghan T, Boswell T, Mahida YR: Recent advances in Clostridium difficile-associated disease. Gut 2008, 57:850-860.

doi:10.1186/1748-717X-6-89

Cite this article as: Hautmann et al:: Clostridium difficile-associated diarrhea in radiooncology: an underestimated problem for the feasibility of the radiooncological treatment? Radiation Oncology 2011 6:89. 